\title{
BNDES TEM O DEVER DE COLABORAR COM A TRANSPARÊNCIA DOS GASTOS PÚBLICOS
}

\author{
Coluna publicada em 17.11.2015: <http://www.conjur.com.br/2015-nov-17/ \\ contas-vista-bndes-colaborar-transparencia-gastos-publicos $>$
}

Um dos aspectos mais relevantes, verdadeiro fundamento e pilar da gestão fiscal responsável, hoje erigido à condição de princípio constitucional de Direito Financeiro, é a transparência fiscal.

Tornar públicos e claros os atos relacionados à administração das finanças públicas é cada vez mais um imperativo da moderna gestão pública e do Estado Democrático de Direito, que não se coadunam com o segredo e a obscuridade, especialmente quando se lida com o dinheiro público.

Contudo, não se trata de tarefa simples, e não me refiro apenas às óbvias resistências daqueles que não querem ter seus malfeitos revelados, mas também às dificuldades para dar transparência a atos que são por demais complexos, fazendo com que não seja fácil levar informações ao conhecimento público de forma que possam ser compreendidas, sem o que a transparência se torna inútil ${ }^{1}$.

É um problema sempre presente nas questôes financeiras, uma vez que as leis orçamentárias e os demonstrativos de contabilidade pública são documentos técnicos, que não estão escritos de forma acessível ao leitor leigo, exigindo formação especializada para que se possa ter pleno domínio das informações que nela estão contidas.

Por isso, devem ser incentivados os instrumentos e meios que permitam traduzir essas informações em linguagem simples, para que todos possam ter plena

1 Como já mencionei anteriormente, a "transparência não se resume a tornar públicas as informações. É preciso que sejam compreensíveis e úteis” (Um ano depois, fica a pergunta: quem pagou a conta dos protestos de junho?, nesta edição, p. 173-176. 
ciência do que está sendo feito com o dinheiro público, até para que seja possível acompanhar os gastos, fiscalizar a administração pública e opinar por ocasião da definição de onde os recursos devam ser aplicados.

Só para que se tenha uma ideia, o orçamento da administração pública federal, conforme proposta apresentada para o exercício financeiro de 2016, é da ordem de 3 trilhões de reais; no Estado de São Paulo, supera os 200 bilhões de reais. Nesses números gigantescos, cada centavo deverá ter sua aplicação especificada, e não é fácil saber exatamente onde estão.

Questôes conceituais, envolvendo a organização dos orçamentos públicos e a natureza das despesas, geram dúvidas e dificuldades na sua contabilização e inserção nos orçamentos públicos.

É o caso, por exemplo, de despesas que representam quantias cada vez mais expressivas de recursos, e que tendem a ficar à margem da lei orçamentária, compondo o que já se conhece como off-budget expenditures, tais como os gastos tributários e os benefícios creditícios, cuja não contabilização adequada acarreta grande prejuízo à transparência fiscal.

Os "gastos tributários" - que compreendem o conjunto de renúncias fiscais de diversas naturezas, como isenções, anistias, remissões, subsídios e outras operações assemelhadas -, embora não configurem "despesas", em uma interpretação restritiva do termo, no sentido de não importarem em efetivo desembolso de recursos financeiros, hoje se integram ao conceito de gasto público. Estudos e trabalhos desenvolvidos principalmente a partir da década de 1960, com destaque para os de Stanley Surrey sobre os tax expenditures, não deixam mais dúvidas quanto à necessidade de contabilizá-los. E nossa Constituição foi atenta a isto, exigindo que as leis orçamentárias contenham demonstrativo regionalizado dos efeitos dos gastos dessa natureza sobre as receitas e despesas (Constituição, art. 165, $\left.\$ 6^{\circ}\right)^{2}$.

Trata-se de questão que vem avançando lentamente em matéria orçamentária, havendo ainda orçamentos que não os contemplam, outros que o fazem de forma pouco específica e detalhada, ou de forma incompleta.

Outra espécie de despesa off-budget que exige atenção e tem se mostrado cada vez mais relevante são os benefícios creditícios.

Tema ainda pouco explorado no Direito Financeiro, as operações de crédito realizadas pelos bancos de fomento, como o BNDES, e a concessão de garantias

2 Demonstrativo que tem caráter informativo, ou seja, a despesa relativa aos benefícios creditícios não necessita de autorização orçamentária prévia. 
pelo Poder Público a empréstimos realizados por terceiros, estão ocupando o noticiário de forma frequente nos últimos meses. ${ }^{3}$

Recentemente foi constituída a “CPI do BNDES”, uma Comissão Parlamentar de Inquérito destinada a investigar supostas irregularidades envolvendo o Banco Nacional de Desenvolvimento Econômico e Social, ocorridas entre os anos de 2003 e 2015, relacionadas à concessão de empréstimos suspeitos e prejudiciais ao interesse público.4

Os principais motivos que deram origem à instalação da CPI foram os empréstimos concedidos de forma pouco transparente a países como Angola e Cuba, dadas as restrições impostas para acessar os documentos dessas transações, empréstimos suspeitos a empresas investigadas na operação "lava-jato", além de empréstimos e garantias de duvidoso interesse público, como os concedidos ao empresário Eike Batista e empresas do setor frigorífico. ${ }^{5}$

Os empréstimos realizados por instituições como o BNDES não seguem os mesmos critérios das instituições financeiras do setor privado. Os bancos públicos operam com linhas de crédito subsidiadas, geralmente na modalidade de crédito direcionado, que, como próprio nome diz, é uma modalidade de crédito destinada a determinados setores ou atividades.

Tendo em vista que o Tesouro Nacional não tem recursos disponíveis para emprestar ao BNDES, acaba emitindo títulos da dívida pública, com remuneração superior àquela pela qual o banco paga à União, gerando uma diferença entre o custo de captação dos recursos e a taxa de retorno, criando uma espécie de "gasto atípico" denominado de "benefício ou subsídio creditício". ${ }^{6}$

3 Trabalhador perde R \$ 1,1 bi por ano com financiamento do BNDES a exportação de serviços, diz estudo. O Globo.com, em 16 de junho de 2015; Pedaladas bancam grandes empresas e produtores rurais. Folha de S.Paulo, manchete de 26 de outubro de 2015.

4 Criada em 17 de julho de 2015 e constituída em 6 de agosto.

5 BRASIL, Senado Federal, CPI do BNDES, Requerimento RCP 14, de 2015.

6 O Tribunal de Contas da União (Acórdão 1.718/2005 - Plenário), define benefícios ou subsídios creditícios como "os gastos decorrentes de programas oficiais de crédito que oferecem condiçôes mais acessíveis para os tomadores de empréstimo que os recursos oferecidos no mercado financeiro, também denominados subsídios implícitos ou indiretos, em função de não constarem no Orçamento Geral da União, embora se ressalte o aspecto de que os recursos do Tesouro a eles alocados têm taxa de retorno inferior ao seu custo de captação (ou seja, há um custo sendo suportado)”. O mesmo conceito é adotado pela Secretaria de Política Econômica (SPE) do Ministério da Fazenda no documento denominado "Orçamento de Renúncias Fiscais e Subsídios da União". No referido documento, distinguem-se os chamados "benefícios financeiros", ou subsídios explícitos, dos "benefícios creditícios", ou subsídios implícitos. Os 
E os valores envolvidos estão longe de serem pequenos. Uma estimativa desses benefícios pode ser calculada aplicando-se o diferencial de juros ao estoque da dívida que o BNDES tem com a União, que atualmente supera os 400 bilhões de reais. Para 2015, foi estimado pela SPE em R $\$ 25$ bilhôes. ${ }^{7}$ Trata-se de um montante considerável, tal como o gasto com o Programa Bolsa-Família, o que fez com que muitos o denominassem "Bolsa-Empresário", uma vez que os recursos do BNDES são canalizados para determinados setores empresariais. ${ }^{8}$

Essa atuação do banco de fomento deveria estar pautada para suprir falhas do mercado de crédito, em especial na oferta de crédito para projetos de longo prazo de maturação, tais como os de infraestrutura, que não despertam muito interesse do setor financeiro privado, em face dos riscos envolvidos e da demora no retorno do investimento.

Imprescindível que essa ação seja dotada de total transparência, não só para que todos tenham ciência do que está sendo feito com o dinheiro que é de todos nós, mas também para se apurar e constatar a eficiência, eficácia e efetividade dos programas que utilizam os benefícios creditícios como instrumentos, e vem sendo objeto de atenção por parte do TCU (Acórdão 3.071/2012 - Plenário).

Neste sentido, Emerson Gomes, em obra recém-publicada ( $O$ direito dos gastos públicos no Brasil), defende a adoção de um conceito amplo de despesa pública que abarque tanto as despesas orçamentárias quanto as despesas off-budget. Ambas são instrumentos de políticas ou programas públicos e apresentam impacto nas variáveis fiscais, seja na receita, despesa ou na dívida públicas, a elas aplicando-se os princípios jurídicos de cunho constitucional, tais como a legitimidade, a economicidade, a eficiência e a transparência: "o gasto tributário é um instrumento de políticas públicas, que tem objetivos específicos a serem atendidos. Se estes objetivos são ilegítimos, também será ilegítimo o gasto tributário. Pode-se apurar se estes objetivos estão sendo atingidos (eficácia) e se eles estão sendo atingidos com o menor gasto tributário possível (eficiência).” Essas mesmas consideraçôes aplicam-se aos benefícios creditícios e são evidenciadas em deliberações do Tribunal de Contas da União (Acórdão 1.718/2008 - Plenário e Acórdão 3.071/2012 - Plenário). ${ }^{9}$

primeiros constam expressamente da lei orçamentária anual, sendo considerados 'subvenções econômicas', os segundos não constam do orçamento público.

7 Conforme o Relatório Preliminar das Contas de Governo 2014, elaborado pelo TCU.

8 Subsídios do governo ao BNDES custarão R\$ 184 bi aos cofres públicos. Jornal O Globo, em 10 de agosto de 2015; Subsídios à economia custam oito vezes mais que o Bolsa-Família. O Estado de S.Paulo, em 28 de agosto de 2011.

9 GOMES, Emerson C. S. O direito dos gastos públicos no Brasil, São Paulo, Almedina, 2015, p. 158-164. 
Os vários fatos que deram origem à "CPI do BNDES", no entanto, levantaram suspeitas sobre várias das operaçôes realizadas, tanto no que se refere aos valores envolvidos, quanto a critérios que levaram à escolha dos beneficiários, à viabilidade financeira, ao retorno do investimento e às garantias concedidas.

Com o veto da Presidente Dilma Rousseff ao texto aprovado pelo Congresso Nacional que acabava com o sigilo dos empréstimos e financiamentos concedidos pelo BNDES, o princípio da transparência fiscal viu-se ameaçado. ${ }^{10}$

Foi necessária a intervenção do Poder Judiciário para restabelecer a prevalência da máxima publicidade dos atos relacionados à administração financeira do Estado.

Em ações movidas pelo jornal Folha de S.Paulo, o Banco foi obrigado a fornecer as informações solicitadas acerca dos empréstimos e financiamentos. ${ }^{11}$

O BNDES impetrou no STF mandado de segurança (MS 33.340) contra a decisão do TCU que determinou que o banco enviasse as informações sobre as operaçôes realizadas com o grupo JBS/Friboi, tendo o relator, Ministro Luiz Fux, deixado claro que o "sigilo de informações necessárias para a preservação da intimidade é relativizado quando se está diante do interesse da sociedade de se conhecer o destino dos recursos públicos", não aceitando a máxima de que "o segredo é a alma do negócio" para as situações que envolvam dinheiro público: "quem contrata com o poder público não pode ter segredos, especialmente se a revelação for necessária para o controle da legitimidade do emprego dos recursos públicos”, devendo prevalecer no Estado Democrático de Direito o dever de máxima transparência. A decisão também deixou claro que as operações financeiras que envolvam recursos públicos não estão abrangidas pelo sigilo bancário a que alude a Lei Complementar n. 105/2001. Ainda que o TCU não possa decretar a quebra do sigilo bancário e empresarial de terceiros, este sigilo não pode ser oponível no caso concreto, pois os dados em questão (operações financeiras com recursos de origem pública) não estão acobertados pela proteção a que a lei se refere. ${ }^{12}$

10 Dilma veta o fim do sigilo das operações do BNDES, g1.globo.com, em 22 de maio de 2015, em referência à lei aprovada em 21 de maio de 2015 (Lei 13.126).

11 ConJur, Liminar obriga BNDES a liberar relatórios sobre empréstimos para jornal, publicada em 21 de agosto de 2015; BNDES deve fornecer ao TCU, independente de decisão judicial, dados de operação financeira. Informativo Migalhas, 27 de maio de 2015. Em sentido semelhante a decisão do TRF-2, que concedeu liminar determinando que o BNDES entregue à Folha de S.Paulo cópias de relatórios que fez para conceder empréstimos acima de $\mathrm{R} \$ 100$ milhões entre abril de 2011 a dezembro de 2014 e TRF-2 libera à Folha acesso a lista de empréstimos do BNDES, ConJur, publicada dia 10 de outubro de 2013.

12 STF, 1a Turma, MS 33.340-DF, rel. Min. Luiz Fux, j. 26.5.2015. 
Como bem expressou o ex-deputado Fernando Gabeira em recente artigo no jornal O Estado de S.Paulo, "num banco que move dinheiro público, um segredo não é a arma do negócio", e, citando Cazuza, exige o que todos queremos e temos o direito de saber: "mostre sua cara, qual é o seu negócio, o nome do seu sócio"13.

13 A agonia de um segredo. O Estado de S.Paulo, 13 de junho de 2015. 